\title{
Reevaluating Muscle Biopsies in the Diagnosis of Pompe Disease: A Corroborative Report
}

\author{
Angela Genge, Natasha Campbell
}

\begin{abstract}
Background: Previous reports suggest that although a diagnostic muscle biopsy can confirm the presence of Pompe disease, the absence of a definitive biopsy result does not rule out the diagnosis. Methods: In this study, we reviewed patients with a limbgirdle syndrome who demonstrated nonspecific abnormalities of muscle, without evidence of the classical changes of acid maltase deficiency. These patients were rescreened for Pompe disease using dried blood spot (DBS) testing. Results: Twenty-seven patients provided blood samples for the DBS test. Four patients underwent subsequent genetic testing. Genetic analysis demonstrated that one patient tested positive for Pompe disease and one patient had one copy of a pathogenic variant. Conclusions: In conclusion, the ability of a diagnostic muscle biopsy to definitively rule out the presence of Pompe disease is limited. There is a role for a screening DBS in all patients presenting with a limb-girdle syndrome without a clear diagnosis.
\end{abstract}

RÉSUMÉ: Réévaluer l'utilité de la biopsie musculaire pour diagnostiquer la maladie de Pompe : Une étude confirmatoire. Contexte: Bien que la biopsie musculaire puisse confirmer un diagnostic de maladie de Pompe, des rapports parus antérieurement suggèrent qu'on ne peut exclure un tel diagnostic même en l'absence de résultats définitifs de biopsie. Méthodes: Dans cette étude, nous nous sommes penchés sur les cas de patients atteints de dystrophie musculaire des ceintures qui présentent des anomalies musculaires non spécifiques. Précisons qu'il s'agissait de patients chez lesquels des preuves de changements habituels en matière de déficit en maltase acide n'avaient pas été trouvées. On a alors procédé à un nouveau dépistage de la maladie de Pompe chez ces patients au moyen de l'analyse de gouttes de sang séché («DBS » en anglais). Résultats: Vingt-sept patients ont fourni des échantillons sanguins pour cette analyse. Ultérieurement, quatre patients ont aussi fait l'objet de tests génétiques ayant montré que l'un d'entre eux était atteint de la maladie de Pompe tandis qu'un autre possédait une copie d'un variant pathogène. Conclusions: L'efficacité de la biopsie musculaire demeure limitée si l'on veut exclure catégoriquement qu'on ait affaire à la maladie de Pompe. L'analyse de gouttes de sang séché peut donc s'avérer utile pour tous les patients qui présentent une dystrophie musculaire des ceintures sans qu'un diagnostic clair n'ait toutefois été établi.

Keywords: Acid maltase deficiency, Dry blood spot, Glycogen storage disease, Muscle biopsy, Pompe disease doi:10.1017/cjn.2016.29

Can J Neurol Sci. 2016; 43: 561-566

Pompe disease, also known as acid maltase deficiency and glycogen storage disease type II, is a rare autosomal recessive progressive neuromuscular disease. It is considered a metabolic myopathy caused by the deficiency of acid alpha glucosidase (GAA), an enzyme that degrades lysosomal glycogen. This GAA deficiency causes glycogen to accumulate in multiple tissues, especially skeletal and cardiac muscle. ${ }^{1}$

Pompe disease patients have mutations in both copies of the GAA gene, which is found on chromosome 17. These mutations lead to varying degrees of GAA deficiency. In patients with the infantile-onset form, enzyme activity is either totally or virtually absent. Some residual enzyme activity is present in the later onset cases, either in childhood or adulthood. The pathological mutations are numerous and appear to have regional specificity. The Arg854X nonsense mutation, for example, is found in many affected African or African-American infants. ${ }^{2}$ However, the majority of mutations identified come from Europe, North America, and Taiwan. ${ }^{3-5}$ As next-generation sequencing of genes becomes more common, a number of mutations are being identified that are new or of undetermined significance. ${ }^{6,7}$

The primary defect in acid maltase deficiency is the progressive intralysosomal accumulation of glycogen without

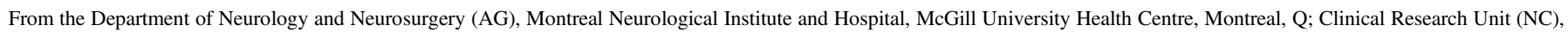
Montreal Neurological Institute and Hospital, McGill University Health Centre, Montreal, QC, Canada.

Received OCtober 13, 2015. Date of Acceptance February 1, 2016.

Correspondence to: N. Campbell, Montreal Neurological Institute and Hospital, Clinical Research Unit, 3801 University Street, Suite 207, Montreal, QC, H3A 2B4, Canada.

Email: natasha.campbell@mail.mcgill.ca 
degradation to glucose. It is believed that the excessive intralysosomal glycogen accumulation causes rupture of the lysosomal membranes. Glycogen and other intralysosomal materials then spill into the cytoplasm, with eventual displacement of the contractile elements of the muscle fibers. There appears to also be a failure of productive autophagy with subsequent skeletal muscle damage.

In the classic infantile form, the deposition of glycogen in the heart, skeletal, and respiratory muscles causes severe cardiomyopathy, hypotonia, and respiratory failure. If left untreated, this leads to death within the first year of life. ${ }^{8,9}$ In late-onset Pompe disease, for both children and adults, the rate of disease progression is variable and deficits are confined mainly to the skeletal and respiratory muscles. Typically, the presentations are a progressive limb-girdle syndrome with respiratory failure. However, over the past few years, it has become clear that patients can have variations such as neuromuscular respiratory failure without significant skeletal muscle involvement. ${ }^{10-12}$ In addition, cases have been identified in which skeletal muscle pain is the predominant clinical feature. $^{13}$

The frequency of Pompe disease in the general population is not entirely known; however, the reported frequency of infantile Pompe disease ranges from 1 in 33,333 to 1 in 138,000. ${ }^{5,14}$ Based on carrier frequencies of three common gene mutations found in the Dutch population, the estimated frequency of late-onset Pompe disease is 1 in $57,000 .{ }^{14}$ Other estimates, such as a study in an ethnically diverse New York population, suggest a frequency of 1 in $40,000 .^{15}$

No specific treatment was available for Pompe disease until 2006, when enzyme replacement therapy with alglucosidase alfa (rhGAA; Myozyme) was approved for all patients with Pompe disease in the United States and the European Union. ${ }^{16}$ The approval was extended to include patients with late-onset Pompe disease after completion of a double-blinded study demonstrating efficacy of Myozyme, specifically with an improvement in walking distance and stabilization of respiratory function over an 18-month period, in 90 patients with proven Pompe disease (GAA deficiency and 2 GAA gene mutations). ${ }^{17}$ Since that time, Myozyme has been approved in Canada for both infantile and late-onset Pompe disease treatment.

One critical issue that has emerged is the under identification of patients with late-onset Pompe disease based upon the understood incidence and prevalence of the disease. It is known that the time from symptom onset to confirmed diagnosis can be from 5 to 30 years in almost one-third of patients. ${ }^{18} \mathrm{~A}$ variety of factors appears to contribute to the delay in diagnosis. Recognition of the limb-girdle distribution of weakness as a clinical picture of late-onset Pompe disease is one factor. This is the only noninflammatory myopathy that is treatable; however, this is not widely known in the general medical community, therefore a specific diagnosis may not be aggressively pursued. In addition, the electromyography results may be very benign leading to underrecognition of the condition. If the respiratory system is the sole affected area, Pompe disease may not even be considered. Experienced neuromuscular clinicians do not necessarily pursue the diagnosis if the clinical phenotype does not include both limbgirdle weakness and respiratory involvement.

A significant contributing factor to identification and treatment of this disease has been the use of muscle biopsy as the gold standard of diagnosis for all forms of muscle disease, including muscular dystrophies, inflammatory myopathies, and particularly the metabolic myopathies, of which Pompe disease is currently the only treatable form. ${ }^{19}$ European studies have shown that even in genetically proven Pompe's, the muscle biopsy can be normal in $20 \%$ to $30 \%$ percent of cases. ${ }^{12,20}$ If screening for the reduced GAA enzyme levels is not part of the diagnostic workup, a significant number of cases of Pompe's can be missed or misdiagnosed. Unfortunately, a patient opportunity for appropriate therapy to stabilize or improve their condition is then lost.

The Montreal Neurological Institute and Hospital (MNH) has one of the largest banks of patient muscle biopsy samples known. The physician who pioneered this bank reserved a small piece of tissue from every muscle biopsy taken at the MNH from 1967 until his death in 2009. The total number of documented samples is more than 1500 . The purpose of the bank was to allow the muscle specimens to be restudied as new diagnostic techniques became available. This has been used successfully in a large number of patients over the decades, providing accurate diagnoses as the field developed. The tradition has continued until the present.

Given the history of myopathology at the MNH and the access to patients, their clinical phenotypes, pathological results, and specimens, a retrospective study was initiated to review the diagnosis of all patients who presented with a limb-girdle phenotype but who remained without a conclusive diagnosis after a muscle biopsy was performed.

This study was undertaken to review a population of patients with a limb-girdle presentation who had a muscle biopsy performed and interpreted as "nonspecific myopathy" by a world renowned myopathologist. Herein we aim to determine how many cases were not diagnosable on the biopsy alone.

\section{Materials ANd Methods}

This retrospective chart review study was approved by the Montreal Neurological Institute and Hospital Research Ethics Board.

The inclusion and exclusion criteria for the study were as follows:

1. Include all patients with a limb-girdle syndrome seen in clinic between 2000 and 2009:

a. The patient should have signs and symptoms of weakness of the limb-girdle muscles.

2. Include all patients with a nonspecific myopathy seen in clinic between 2000 and 2009.

a. For patients with a nonspecific myopathy: These patients should have a clinical history that suggests weakness of skeletal or respiratory muscles. We also accepted patients with either a history of exercise intolerance, myalgias, or asymptomatic patients or who have clear signs of myopathy (elevated creatinine kinase, myopathic electromyography).

\section{Exclude the following types of patients:}

a. Any patients for whom the diagnosis (i.e. the cause of the myopathy) had already been determined were excluded. A search of the database for repeat biopsies was made to exclude patients who had a subsequent diagnostic biopsy. 
b. Patients were excluded if clinical or biopsy features were present that would be incompatible with a diagnosis of Pompe disease, such as:

i. peripheral neuropathy

ii. Central nervous system disorder: dementia, movement disorder

iii. Cerebellar disorder

c. Also excluded were patients if:

i. No history (clinical data) was available

Written invitations in French and English and the informed consent form were sent to each patient by mail, and telephone contact was attempted. For patients who agreed to participate, a clinic visit was arranged to discuss their participation and to obtain informed consent. Participating patients first completed the dry blood spot (DBS) test to measure GAA enzyme activity.

The DBS test is a minimally invasive procedure that requires about $100 \mu \mathrm{l}$ of blood obtained by a routine lancet puncture of a fingertip or by standard venipuncture. Trained health care personnel obtain the blood, which is then sent to Warnex Laboratories in Laval, Quebec, for processing. If the blood test results are negative (no reduction in GAA enzyme activity demonstrated), no further testing is required. If the results are positive or borderline positive (GAA enzyme activity is reduced), the patient then returns for full GAA gene sequencing.

The secondary testing consisted of taking approximately $5 \mathrm{ml}$ of blood from each patient. These samples were sent to the Children's Hospital of Eastern Ontario for specialized genetic testing. DNA results were based on sequencing of the complete coding region, $3^{\prime}$ untranslated region, and flanking intronic sequences from exons 2 through 20 of the GAA gene. This analysis did not detect mutations within the GAA regulatory region, exon 1, or most of the intronic sequence, nor did it detect large gene rearrangements.

Based on the genetic sequencing, any patient diagnosed with Pompe disease was assessed in the neuromuscular clinic at the $\mathrm{MNH}$ and provided with follow-up. All biopsies performed for diagnostic purposes at the $\mathrm{MNH}$ over the period reviewed were open muscle biopsies taken from one of four sites: deltoid, biceps, quadriceps, and gastrocnemius. The site chosen was based upon clinical muscle involvement in the form of weakness of the selected muscle or, more rarely, myalgias occurring in the affected muscle. The four muscles groups identified are those for which there are well-established normal and disease patterns.

\section{Results}

One hundred and seventy patient biopsies within the database of the pathology laboratory of the MNH were reviewed. These biopsies were primarily taken between 2002 and 2009. Seventytwo patients had a clinical profile suggestive of a limb-girdle syndrome, but their muscle biopsy was not diagnostically informative. Twenty-seven patients were ultimately reachable and agreed to participate in the study. A number of patients were identified but were lost to follow-up. They could not be contacted through the data available at the MNH (e.g. phone numbers were out of service, home addresses were outdated). See Figure 1 for a schematic representation of the study plan.

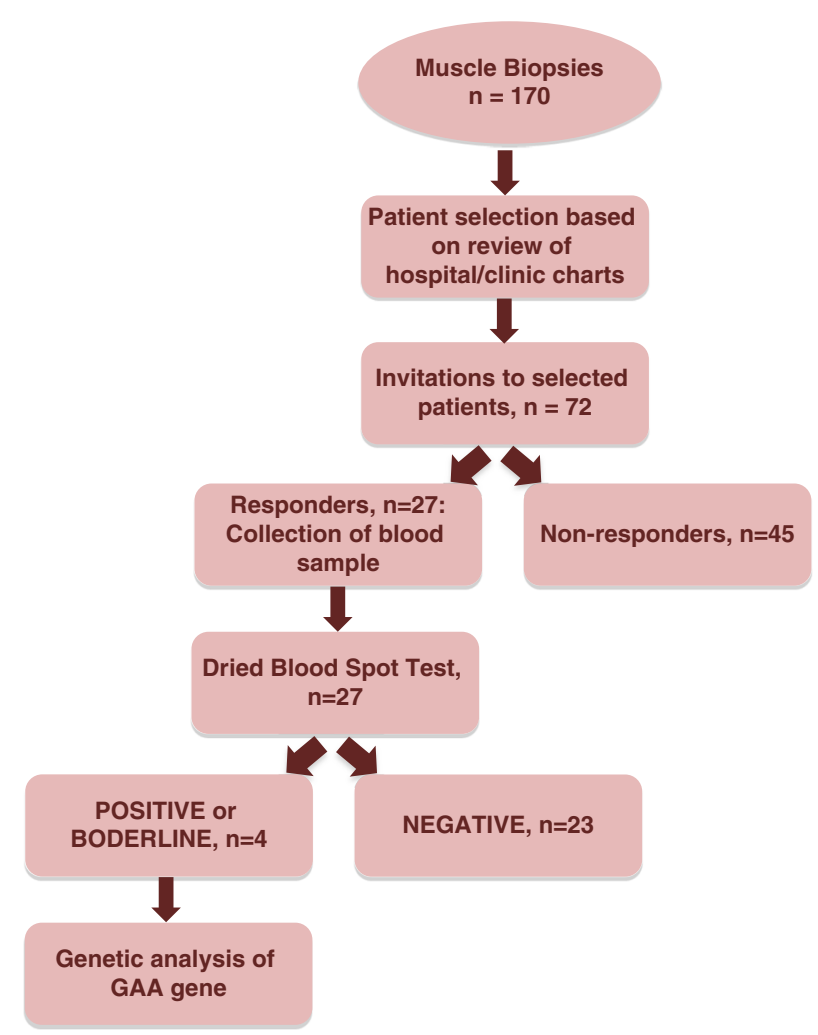

Figure 1: Flowchart of study design.

The normal reference range of GAA is 4.96 to $27.30 \mathrm{pmol} /$ hour/punch. The reference range for low GAA levels, signalling that patients should undergo genetic testing, is 0.00 to $4.49 \mathrm{pmol} / \mathrm{hour} / \mathrm{punch}$. The borderline reference range is 4.50 to $5.39 \mathrm{pmol} / \mathrm{hour} / \mathrm{punch}$ whereby additional testing (mutation analysis or enzyme activity in a second sample) is recommended. Borderline values were flagged as such. Of the 27 DBS samples analyzed, three patients tested positive and one patient was borderline positive (GAA activity was at the limit of being reduced). In other words, $14.8 \%$ of the patients tested had reduced GAA activity. The remainder of the samples had normal GAA activity ranging from 5.77 to $18.38 \mathrm{pmol} /$ hour/punch.

Genetic analysis demonstrated that one patient tested positive for Pompe disease, and one patient had one copy of a pathogenic variant detected (Table 1). When inherited with another GAA pathogenic variant, this variant is associated with adult-onset Pompe disease. A second GAA pathogenic variant was not detected in this individual; therefore, a diagnosis of Pompe disease was not confirmed. Total genome sequencing to identify new mutations was not performed.

The affected patient in our study was a 54-year-old French-Canadian male. Genetic analysis demonstrated two pathogenic variants in this individual. A $T$ to $G$ variant 13 nucleotides $5^{\prime}$ of exon 2 in intron 1 of the GAA gene was detected (c. [-32-13T $>$ G]). This variant has been reported previously as a mild mutation resulting from the creation of a leaky splice site that results in incomplete processing of messenger RNA. However, a proportion of the messenger RNA is complete 
Table 1: Muscle biopsy finding, reduced activity of GAA and genetic test results of four patients

\begin{tabular}{|c|c|c|c|}
\hline Patient number (gender, age) & Muscle Biopsy Finding & GAA (pmol/h/punch)* & Genetic Testing Results \\
\hline 1 (female, 64) & $\begin{array}{l}\text { Chronic myopathy of undetermined type, no distinguishing } \\
\text { features (left deltoid) }\end{array}$ & $3.61^{\dagger}$ & Patient deceased; genetic testing not completed \\
\hline 2 (male, 60) & Minor nonspecific alterations (left deltoid) & $3.65^{\dagger}$ & $\begin{array}{l}\text { One copy of c. }[-32-13 \mathrm{~T}>\mathrm{G}] \text { GAA pathogenic } \\
\text { variant detected } \\
\text { Unable to confirm a diagnosis of Pompe disease }\end{array}$ \\
\hline 3 (female, 44) & Borderline, slightly abnormal muscle biopsy (left biceps) & $4.58^{\ddagger}$ & No pathogenic variants detected \\
\hline 4 (male, 54) & $\begin{array}{l}\text { Nonspecific abnormalities; evidence of acid maltase } \\
\text { deficiency myopathy is absent (left biceps) }\end{array}$ & $0.87^{\dagger}$ & $\begin{array}{l}\text { c. }[-32-13 \mathrm{~T}>\mathrm{G}] ;\left[2481+110 \_2646+39 \mathrm{del}\right] \\
\text { GAA genotype } \\
\text { Positive for Pompe disease }\end{array}$ \\
\hline
\end{tabular}

*Normal reference range of GAA is $4.96-27.30 \mathrm{pmol} / \mathrm{h} / \mathrm{punch}$.

${ }^{\dagger}$ GAA activity reduced.

${ }^{\ddagger}$ GAA activity at the limit of being reduced.

and therefore some GAA is produced from this allele. In addition, this patient was found to have the common deletion of exon 18 of the GAA gene.

In terms of family history, the patient's mother had six miscarriages and died at age 75 of lung cancer. His father died of cardiac problems in his early sixties. It appears that no other family members, including his parents and two siblings, were affected.

The patient had normal development as a child but began to develop proximal leg weakness by the age of 18 . His medical history is significant for high blood pressure as well as dyslipidemia, previous appendectomy, and peptic ulcer disease. He has no allergies, stopped smoking in 2002, and denied any alcohol or drug use. The patient was hospitalized in 2002 for several episodes of loss of consciousness. One of these episodes required intubation and tracheostomy. Since then, he has been dependent on continuous positive airway pressure or bilevel positive airway pressure when he is lying flat or sleeping. Electromyography demonstrated denervation of the diaphragm only, and the clinical picture remained one of isolated bilateral diaphragmatic paralysis likely on the basis of axonal damage or of a muscle dysfunction involving both diaphragms. During this time, the possibility of acid maltase deficiency was entertained but ruled out based on the muscle biopsy. When he was seen at the MNH, he complained of dyspnea with minimal effort and significant orthopnea. The patient is has been treated with Myozyme since the diagnosis of Pompe disease was confirmed.

Since beginning Myozyme treatment, the patient reports significant improvement. Subjectively, at his 6-month visit, the patient said he felt " $80 \%$ better." His myalgias are almost completely resolved. The parameters typically followed at our center during enzyme replacement therapy for Pompe patients include pulmonary function test results (forced expiratory volume in 1 second, forced vital capacity), physiotherapy test results (Medical Research Council scale strength testing, timed up-and-go test, 2- and 6-minute walks), as well as routine blood tests and monitoring of immunoglobulin $\mathrm{G}$ antibody levels. The patient is now functionally better: he can mow the lawn (which he was unable to do previously) and walk for a longer time and distance. However, shortness of breath is unchanged and the patient continues to be continuous positive airway pressure-dependent at night. The patient continues to be followed at the $\mathrm{MNH}$.

\section{DISCUSSION}

The recognition that muscle biopsy alone is insufficient to diagnose Pompe disease is critical. Our retrospective study demonstrates that even in the best of hands and with the most experienced of myopathologists, the diagnosis can be missed on biopsy as the classical pathology can be absent from the tissue sample taken. In addition with the development of an accurate screening test (DBS testing), muscle biopsy can be avoided altogether.

Our findings corroborate previous reports found in larger and prospective series. For example, in a sample of 126 patients from the French Pompe Registry, muscle biopsies showed specific features of Pompe disease in fewer than two-thirds of the cases. $^{21}$ Another Pompe registry examined the diagnostic methods used for 1059 Pompe disease patients. ${ }^{22}$ The study found that, over time, the use of muscle biopsy as a diagnostic tool decreased, and the use of blood-based assays increased. Because the clinical phenotype of the disease is so varied, muscle biopsies lack the sensitivity required for diagnosis. Earlier papers have also suggested that not only genetic testing but quantitative tissue analysis (muscle, fibroblast culture, and/or lymphocytes) for GAA activity may also serve as gold standard diagnostic tests. $^{23}$ Blood-based assay such as DBS testing, however, appear to result in a more timely diagnosis across the clinical spectrum of Pompe disease. ${ }^{22}$ Despite this growing evidence, however, clinical guidelines for the diagnosis of Pompe disease remain unclear.

Adult-onset Pompe disease is the only known noninflammatory myopathy that has an approved effective therapy in the form of Myozyme. Therefore, even though it is considered less frequent than other causes of the limb-girdle or neuromuscular respiratory clinical phenotype, it is important to correctly identify these patients to minimize the historical delay in diagnosis and therefore the delay in initiation of therapy.

In the infantile form of the disease, it is clear that early diagnosis and treatment leads to much better outcomes. ${ }^{24}$ In the late-onset form, the slowly progressive nature of this condition and that therapy has been available for only a short period means 
that further longitudinal data are required to consider the effect of early treatment in these patients. A recent study, however, demonstrated that length of time on enzyme replacement therapy was associated with significant increases in walking distance and muscle strength scores. ${ }^{25}$ It is very likely that, similar to the infantile form of the disease, early treatment initiation will also lead to better outcomes for late onset patients.

This retrospective review was limited by the number of patients we were able to contact. Even with the reduction, the number of newly identified potential patients (with reduced enzymatic activity) was considerable. However, several conclusions can be drawn:

1. A negative or nonspecific muscle biopsy report does not rule out the possibility of Pompe disease in a patient with the appropriate clinical phenotype.

2. DBS testing is a useful screening tool for Pompe disease and can be performed in a reliable manner with minimal resources in patients with the appropriate presentations.

3. If a therapy is available and diagnostic testing is accurate, neuromuscular physicians have an obligation to screen for even rare diseases such as adult onset Pompe disease.

Future investigations may wish to further expound on whether DBS testing can be used as an early screening test for potential patients with the appropriate clinical presentation. At our center, we have begun to initiate a prospective study in this vein. Currently, all patients who are referred for clinical phenotypes consistent with Pompe disease or a nonspecific myopathy without a clearly identified diagnosis undergo DBS testing at the first consultation in conjunction with other investigative bloodwork and electromyography. The use of DBS as a first step in the evaluation of clinically appropriate patients may also contribute significant savings for the health care system by avoiding unnecessary testing before the diagnosis of Pompe disease.

\section{DisClosures}

This work was funded by Genzyme, a Sanofi company. AG is the principal investigator in the investigator-driven late-onset acid maltase deficiency (LOAMD) trial, sponsored by Genzyme, a Sanofi company. AG and NC have received travel reimbursement from Genzyme. AG is currently on the International Advisory Board for Myozyme of Genzyme.

\section{ACKNOWLEDGMENTS}

The authors thank the patients and health care professionals (Dr. Erin O'Ferrall, Dr. Rami Massie, Wynne Abdon, Ritsa Argyriou) for their kind support. The late Dr. George Karpati designed the study and wrote the protocol. AG and NC recruited patients and did the study research, $\mathrm{NC}$ analyzed the data, AG and $\mathrm{NC}$ authored reviewed and edited initial and final versions, and $\mathrm{AG}$ and $\mathrm{NC}$ reviewed and approved the submitted version.

\section{REFERENCES}

1. Kishnani PS, Steiner RD, Bali D, et al. Pompe disease diagnosis and management guideline. Genet Med. 2006;8:267-88. doi: 10.1097/01.gim.0000218152.87434.f3.

2. Becker JA, Vlach J, Raben N, et al. The African origin of the common mutation in African American patients with glycogen-storage disease type II. Am J Hum Genet. 1998;62:991-4. doi: $10.1086 / 301788$.
3. Huie ML, Chen AS, Tsujino S, et al. Aberrant splicing in adult onset glycogen storage disease type II (GSDII): molecular identification of an IVS1 $(-13 \mathrm{~T} \rightarrow \mathrm{G})$ mutation in a majority of patients and a novel IVS10 $\quad(+1 \mathrm{GT} \rightarrow \mathrm{CT})$ mutation. Hum Mole Genet. 1994;3:2231-6

4. Shieh JJ, Lin CY. Frequent mutation in Chinese patients with infantile type of GSD II in Taiwan: evidence for a founder effect. Hum Mutat. 1998;11:306-12. doi: 10.1002/(SICI)1098-1004 (1998) 11: <306::AID-HUMU8>3.0.CO;2-S.

5. Chien YH, Chiang SC, Zhang XK, et al. Early detection of pompe disease by newborn screening is feasible: results from the Taiwan screening program. Pediatrics. 2008;122:e39-45. doi: 10.1542/ peds.2007-2222.

6. Oba-Shinjo SM, Da Silva R, Andrade FG, et al. Pompe disease in a Brazilian series: clinical and molecular analyses with identification of nine new mutations. J Neurol. 2009;256:1881-90. doi: 10.1007/s00415-009-5219-y.

7. Kroos M, Pomponio RJ, van Vliet L, et al. Update of the Pompe disease mutation database with 107 sequence variants and a format for severity rating. Hum Mutat. 2008;29:E13-26. doi: 10.1002/humu.20745.

8. Kishnani PS, Howell RR. Pompe disease in infants and children. J Pediatr. 2004;144:S35-43. doi: 10.1016/j.jpeds. 2004.01.053.

9. Kishnani PS, Hwu WL, Mandel H, Nicolino M, Yong F, Corzo D. A retrospective, multinational, multicenter study on the natural history of infantile-onset Pompe disease. J Pediatr. 2006;148:671-6. doi: 10.1016/j.jpeds.2005.11.033.

10. Lightman NI, Schooley RT. Aldult onset acid maltase deficiency. Case report of an adult with severe respiratory difficulty. Chest. 1977;72:250-2.

11. Müller-Felber W, Horvath R, Gempel K, et al. Late onset Pompe disease: clinical and neurophysiological spectrum of 38 patients including long-term follow-up in 18 patients. Neuromusc Disord. 2007;17:698-706. doi: 10.1016/j.nmd.2007.06.002.

12. Winkel LPF, Hagemans MLC, Van Doorn PA, et al. The natural course of non-classic Pompe's disease; a review of 225 published cases. J Neurol. 2005;252:875-84. doi: 10.1007/ s00415-005-0922-9.

13. Fernandez C, De Paula AM, Figarella-Branger D, et al. Diagnostic evaluation of clinically normal subjects with chronic hyperCKemia. Neurology. 2006;66:1585-7. doi: 10.1212/01.wnl. $0000216144.69630 .6 \mathrm{e}$.

14. Ausems MGEM, Verbiest J, Hermans MMP, et al. Frequency of glycogen storage disease type II in The Netherlands: implications for diagnosis and genetic counselling. Eur J Hum Genet. 1999; 7(6):713-6. doi: 10.1038/sj.ejhg.5200367.

15. Martiniuk F, Chen A, Mack A, et al. Carrier frequency for glycogen storage disease type II in New York and estimates of affected individuals born with the disease. Am J Med Gene. 1998;79: 69-72. doi: 10.1002/(SICI)1096-8628(19980827)79:1<69::AIDAJMG16> 3.0.CO;2-K.

16. Kishnani PS, Corzo D, Nicolino M, et al. Recombinant human acid $\alpha$-glucosidase: major clinical benefits in infantile-onset Pompe disease. Neurology. 2007;68:99-109. doi: 10.1212/01.wnl. 0000251268.41188 .04$.

17. Van Der Ploeg AT, Clemens PR, Corzo D, et al. A randomized study of alglucosidase alfa in late-onset Pompe's disease. N Engl J Med. 2010;362:1396-406. doi: 10.1056/NEJMoa0909859.

18. Hagemans MLC, Winkel LPF, Van Doorn PA, et al. Clinical manifestation and natural course of late-onset Pompe's disease in 54 Dutch patients. Brain. 2005;128:671-7. doi: 10.1093/brain/awh384.

19. Vissing J, Lukacs Z, Straub V. Diagnosis of pompe disease muscle biopsy vs blood-based assays. JAMA Neurol. 2013;70:923-7. doi: 10.1001/2013.jamaneurol.486.

20. Laforêt P, Nicolino M, Eymard B, et al. Juvenile and adult-onset acid maltase deficiency in France: genotype-phenotype correlation. Neurology. 2000;55:1122-8.

21. Laforet P, Laloui K, Granger B, et al. The French Pompe registry. Baseline characteristics of a cohort of 126 patients with adult Pompe disease. Rev Neurol (Paris). 2013;169:595-602; Epub 2013/09/07. doi: 10.1016/j.neurol.2013.07.002. PubMed PMID: 24008051. 
22. Kishnani PS, Amartino HM, Lindberg C, Miller TM, Wilson A, Keutzer J. Methods of diagnosis of patients with Pompe disease: data from the Pompe Registry. Mol Genet Metab. 2014;113(1-2):84-91. doi: http://dx.doi.org/10.1016/j.ymgme. 2014.07.014.

23. Al-Lozi MT, Amato AA, Barohn RJ, et al. Diagnostic criteria for late-onset (childhood and adult) Pompe disease. Muscle Nerve. 2009;40:149-60. doi: 10.1002/mus.21393.
24. Kishnani PS, Corzo D, Leslie ND, et al. Early treatment with alglucosidase alfa prolongs long-term survival of infants with pompe disease. Pediatr Res. 2009;66:329-35. doi: 10.1203/PDR. 0b013e3181b24e94.

25. Anderson LJ, Henley W, Wyatt KM, et al. Effectiveness of enzyme replacement therapy in adults with late-onset Pompe disease: results from the NCS-LSD cohort study. J Inherit Metab Dis. 2014;37:945-52. doi: 10.1007/s10545-014-9728-1. 